\title{
Desempenho de cultivares de morango submetidas a diferentes tipos de polinização em cultivo protegido
}

\author{
Sidia Witter ${ }^{(1)}$, Bernadete Radin(1), Bruno Brito Lisboa(2), Juliana Stephanie Galaschi Teixeira( ${ }^{(3)}$, \\ Betina Blochtein ${ }^{(4)}$ e Vera Lúcia Imperatriz-Fonseca(3)
}

\begin{abstract}
(1)Fundação Estadual de Pesquisa Agropecuária (Fepagro), Centro de Meteorologia Aplicada, Gonçalves Dias no 570, Menino Deus, CEP 90130-060 Porto Alegre, RS. E-mail: sidia-witter@fepagro.rs.gov.br, Bernadete-radin@fepagro.rs.gov. (2)Fepagro, Laboratório de Solos. E-mail: bruno-lisboa@fepagro.rs.gov.br (3)Universidade de São Paulo, Laboratório de Abelhas, Avenida Bandeirantes, no 3.900, Monte Alegre, CEP 14040-901 São Paulo, SP. E-mail: julianagalaschi@gmail.com, vlifonsec@ib.usp.br (4)Pontifícia Universidade Católica do Rio Grande do Sul, Avenida Ipiranga, o 6.681, CEP 90619-900 Porto Alegre, RS. E-mail: betinabl@pucrs.br
\end{abstract}

Resumo - O objetivo deste trabalho foi avaliar o efeito de diferentes tipos de polinização sobre a qualidade de frutos de cultivares de morangueiro e sua contribuição isolada para a massa dos frutos, bem como determinar o potencial de Plebeia nigriceps (Hymenoptera: Apidae, Meliponini) como agente polinizador em ambiente protegido. As cultivares Aromas, Diamante e Cegnidarem foram submetidas a tratamentos com autopolinização, polinização por P. nigriceps e polinização livre. Os experimentos foram conduzidos em estufa tipo pampeana, coberta com polietileno transparente e desprovida de telas anti-insetos nas laterais, com 1.344 plantas. Para as avaliações, foram marcadas 56 flores primárias em botão, de cada cultivar, e considerou-se cada planta uma repetição. Avaliaram-se massa de matéria fresca, peso, diâmetro, comprimento e presença de deformação nos frutos. A polinização entomófila tem contribuição variada à massa dos frutos, de acordo com a cultivar. As cultivares apresentam sensibilidade variada à autopolinização, no que se refere à incidência de frutos deformados. A interferência da polinização entomófila na produtividade do morangueiro está mais relacionada à redução do percentual de frutos deformados do que ao aumento da massa dos frutos em si. O comportamento de $P$. nigriceps indica que a espécie apresenta potencial para polinização da cultura do morangueiro em ambiente protegido.

Termos para indexação: Fragaria x ananassa, Plebeia nigriceps, autopolinização, produtividade, qualidade de fruto.

\section{Performance of strawberry cultivars subjected to different types of pollination in a greenhouse}

\begin{abstract}
The objective of this work was to evaluate the effects of different types of pollination on the fruit quality of strawberry cultivars, and their isolated contribution to fruit mass, as well as to determine the potential of Plebeia nigriceps (Hymenoptera: Apidae, Meliponini) as a pollination agente in protected environment. The cultivars Aromas, Diamante, and Cegnidarem were subjected to self-pollination, pollination by P. nigriceps, and free pollination treatments. The experiments were carried out in a "pampeana" greenhouse, covered with transparent polyethylene and without anti-insect screens on the sides, with 1,344 plants. For the evaluations, 56 primary flowers of each cultivar, still in bud, were marked, and each of these plants was considered a replicate. Fresh matter mass, weight, diameter, and misshape incidence in fruit were evaluated. The contribution of Entomophilous pollination on fruit weight varies according to the cultivar. Cultivars have different sensibility to self-pollination, regarding misshape incidence on fruit. Entomophilous interference on strawberry yield is more related to reduction of misshape incidence than to increases in fruit mass itself. $P$. nigriceps behavior indicates that this species has good potential for pollinating strawberry crop in protected environment.
\end{abstract}

Index terms: Fragaria x ananassa, Plebeia nigriceps, self-pollination, yield, fruit quality.

\section{Introdução}

O morangueiro (Fragaria $x$ ananassa Duch.) é cultivado nas mais variadas regiões do mundo. No Brasil, a cultura encontra-se difundida em regiões de clima temperado e subtropical e é produzido para consumo in natura ou industrializado (Radmann et al., 2006).
De modo geral, o morangueiro é cultivado em pequenas propriedades e a cultura requer elevado número de trabalhadores ao longo de seu ciclo (Reichert \& Madail, 2003).

O cultivo do morangueiro cresceu nos últimos anos com o uso em larga escala de defensivos agrícolas. O cultivo em sistemas sem solo abre algumas possibilidades no sentido

Pesq. agropec. bras., Brasília, v.47, n.1, p.58-65, jan. 2012 
de combinar ambiente protegido com a eliminação do uso de produtos destinados à desinfecção do solo, além de proporcionar maior produtividade (Fernandes Júnior et al., 2002). Além disso, por meio dessa técnica, podese antecipar o início da colheita e, ainda, aumentar o rendimento por área.

A utilização do ambiente protegido, na cultura do morangueiro, proporciona uma série de vantagens, em que se destaca a proteção da cultura contra condições meteorológicas adversas e ataque de pragas e doenças (Antunes et al., 2007). No entanto, a barreira física imposta pela cobertura de plástico e pelas telas antiafídeos dificulta $o$ acesso de polinizadores às flores do morangueiro (Kakutani et al., 1993). Para Zebrowska (1998), a falta de polinizadores durante a floração ou polinização, associada à quantidade insuficiente de pólen, resulta em deformação dos frutos e em rendimentos comerciais mais baixos. Para Jaycox (1970), as flores das cultivares comerciais são autoférteis, e a polinização pode ser realizada pelo vento, gravidade e insetos; entretanto, diversas cultivares apresentam variações em sua capacidade de autopolinização (Zebrowska, 1998).

No interior de ambiente protegido de produção o vento é praticamente nulo. A introdução de polinizadores na estufa é uma alternativa para compensar esse problema. Espécies de abelhas Meliponini têm sido testadas com sucesso quanto à polinização e produção de morangueiro nesses sistemas de cultivo (Malagodi-Braga \& Kleinert, 2004, 2007; Antunes et al., 2007). A ausência de ferrão funcional torna essas abelhas especialmente adequadas para a polinização de culturas em zonas habitadas ou em ambiente protegido (Slaa et al., 2006). As abelhas Meliponini são consideradas uma alternativa para os serviços de polinização de diversas culturas de impor-tância econômica (Heard, 1999), por serem um grupo de abelhas eussociais altamente diversificado e abundante em regiões tropicais e subtropicais do planeta (Sommeijer \& Ruijter, 1999). Existem aproximadamente 300 espécies descritas, que variam significativamente quanto ao tamanho das colônias, tamanho corporal e estratégia de forrageamento (Slaa et al., 2003; Biesmeijer \& Slaa, 2004; Nieh, 2004). Estas diferenças interespecíficas permitem a seleção da espécie de Meliponini mais adequada à polinização de determinada espécie vegetal e do melhor sistema em que o polinizador pode ser utilizado, ou seja, campo aberto ou ambiente protegido (Slaa et al., 2006).
Plebeia nigriceps (Friese, 1901) é um Meliponini abundante na região sul do Rio Grande do Sul (Witter et al., 2007), popularmente conhecida como mirim. Utiliza espaços pré-existentes em paredes de propriedades rurais para nidificação. Contudo, em razão de seus enxames serem pequenos, constituídos por algumas dezenas de indivíduos, e com baixa produção de mel, eles são pouco valorizados e, por descuido, têm sido largamente destruídos sem mesmo se conhecer o potencial polinizador da espécie em ecossistemas naturais e agrícolas.

Pouca atenção é dada à polinização do morangueiro, embora estudos mostrem que a provisão de polinizadores geralmente resulta em aumento na produção (Malagodi-Braga \& Kleinert, 2004; Antunes et al., 2007; Roselino et al., 2009). Em razão do alto investimento na condução da cultura, com o emprego elevado de mão de obra, irrigação e controle de pragas e doenças, deve-se também avaliar a importância da polinização para o desempenho da cultura (Jaycox, 1970).

O objetivo deste trabalho foi avaliar o efeito de diferentes tipos de polinização sobre a qualidade de frutos de cultivares de morangueiro e sua contribuição isolada para a massa dos frutos, bem como determinar o potencial de Plebeia nigriceps (Hymenoptera: Apidae, Meliponini) como agente polinizador em ambiente protegido.

\section{Material e Métodos}

O estudo foi realizado de agosto a novembro de 2007, na Estação Experimental da Fepagro Saúde Animal, em Eldorado do Sul, RS (3005'S, 5139' W; a $10 \mathrm{~m}$ de altitude). O clima da região conforme a classificação de Köppen é do tipo Cfa, subtropical úmido, com verões quentes.

$\mathrm{O}$ experimento foi conduzido em estufa de plástico tipo pampeana, com estrutura metálica e cobertura em arco, com $21 \mathrm{~m}$ de comprimento e $10 \mathrm{~m}$ de largura $\left(210 \mathrm{~m}^{2}\right)$, coberta com polietileno transparente de $150 \mu \mathrm{m}$ de espessura e desprovida de telas anti-insetos nas laterais. Foram cultivadas 1.344 plantas de morangueiro das cultivares Aromas, Diamante e Cegnidarem, em delineamentointeiramentecasualizado. Uma estrutura de madeira foi montada com prateleiras dispostas a 1,20 m da superfície do solo. Sobre cada prateleira, foram colocadas seis sacolas de polietileno de cor branca, com $3 \mathrm{~m}$ de comprimento e volume de 
aproximadamente $20 \mathrm{~L}$ por sacola, preenchidas com substrato composto de $50 \%$ de turfa e $50 \%$ de casca de arroz queimada. As mudas foram plantadas em fileiras simples com espaçamento de $20 \mathrm{~cm}$ na linha e $22 \mathrm{~cm}$ entre sacolas.

O manejo nutricional foi realizado com o fornecimento de nutrientes via fertirrigação, com três formulações comerciais de fertilizante, uma no período inicial, após a adaptação das mudas (NPK 15-30-15 e, respectivamente, 19,0, 0,60, 0,84 e 0,025 $\mathrm{mg} \mathrm{g}^{-1} \mathrm{de} \mathrm{Ca}$, $\mathrm{Mg}$, S e B), outra durante 20 a 25 dias, na iniciação (NPK 15-5-30 e, respectivamente, 19,0, 1,81, 5,0, $0,025 \mathrm{mg} \mathrm{g}^{-1}$ de $\mathrm{Ca}, \mathrm{Mg}, \mathrm{S}$ e B), e outra durante a maturação (NPK 6-12-36 e, respectivamente, 19,0, 1,81, 2,0, 0,025 $\mathrm{mg} \mathrm{g}^{-1}$ de Ca, Mg, S e B). Foi utilizado fungicida iprodione, quando da incidência do patógeno Botrytis cinerea.

As cultivares foram submetidas aos seguintes tratamentos: autopolinização espontânea, promovida pela ação da gravidade $(\mathrm{G})$; polinização por P. nigriceps, mais a ação da gravidade (PPn); e polinização livre (PL), que compreende o efeito da polinização promovida pela gravidade, vento e insetos. As avaliações foram realizadas durante a primeira floração do morangueiro. Foram marcadas 56 flores primárias, em botão, de cada uma das cultivares, o que totalizou 168 plantas. Considerou-se cada planta uma repetição.

As plantas, nos experimentos de G e PPn, foram cobertas com tela anti-insetos de cor branca, para evitar a saída das abelhas, $1 \mathrm{~m}$ acima das prateleiras; o espaço interno era de 3,96 $\mathrm{m}^{3}$. Duas colônias de P. nigriceps foram colocadas, no início da primeira floração, na área coberta destinada ao experimento (PPn).

No tratamento destinado à polinização aberta para insetos (PL), as flores primárias foram naturalmente visitadas por insetos, em razão da ausência de tela anti-insetos na estufa e da contribuição da ação da gravidade e do vento para a polinização.

Os frutos primários foram colhidos quando apresentavam desde $70 \%$ de cor avermelhada até os completamente maduros. Foram pesados, medidos (diâmetro e comprimento, com uso de um paquímetro) e classificados de acordo com a forma (presença ou ausência de deformação). O grau de deformação foi analisado por avaliação visual, de acordo com critérios previamente estabelecidos: ausência de deformação, ou seja, sem deformação ou com deformação mínima (0-30\%), e com deformação ( $>30 \%$ de deformação nos frutos).
A contribuição dos diferentes tratamentos de polinização na produção foi determinada por meio da contribuição percentual na massa dos frutos primários frescos, em cada tratamento, com adaptação da fórmula proposta por Zebrowska (1998). O tratamento livre foi utilizado como serviço de polinização máxima. Os cálculos foram feitos pelas equações, $\mathrm{G}=\left(\mathrm{X}_{\mathrm{G}} / \mathrm{X}_{\mathrm{PL}}\right) \times 100 \%, \mathrm{PPn}=\left[\left(\mathrm{X}_{\mathrm{PPn}} /\right.\right.$ $\left.\left.\left.\mathrm{X}_{\mathrm{PL}}\right)-\mathrm{X}_{\mathrm{G}}\right)\right] \times 100 \%, \mathrm{PL}=\left[\left(\mathrm{X}_{\mathrm{PL}}-\mathrm{X}_{\mathrm{PPn}}\right) / \mathrm{X}_{\mathrm{PL}}\right] \times 100 \%$, $\mathrm{G}(\%)+\operatorname{PPn}(\%)+\operatorname{PL}(\%)=100 \%\left(\mathrm{X}_{\mathrm{PL}}\right)$, em que: $\mathrm{G}$ é o efeito da autopolinização espontânea, promovida pela ação da gravidade (\% autogamia); PPn é o efeito da polinização por $P$. nigriceps; e PLé o efeito da polinização pelo vento e várias espécies de insetos (polinização livre); $\mathrm{X}_{\mathrm{G}}$ é a massa média dos frutos, após a autopolinização; $\mathrm{X}_{\mathrm{PPn}}$ é a massa média dos frutos, após polinização por P. nigriceps; e $\mathrm{X}_{\mathrm{PL}}$ é a massa média dos frutos, após polinização livre. Flores que não frutificaram e frutos com danos causados por doenças foram desconsiderados.

A análise do comportamento das abelhas, durante suas visitas às flores, no início da primeira floração, foi realizada no interior de uma área com volume de $3,96 \mathrm{~m}^{3}$, coberta com tela fina, com altura de $1 \mathrm{~m}$ acima das prateleiras. $\mathrm{Na}$ área havia 168 plantas de morangueiro das cultivares Aromas, Diamante e Cegnidarem e uma colônia de $P$. nigriceps, assim, as abelhas tinham acesso às flores das três cultivares. O comportamento das operárias foi analisado por meio de 60 observações individuais e diretas das abelhas nas flores. Cada pouso na flor foi considerado uma visita (unidade de observação) e, durante cada exposição, foram registrados os seguintes aspectos do comportamento das abelhas: tempo de permanência da abelha na flor, por meio da cronometragem do tempo desde o pouso até a saída; recurso floral coletado (néctar ou pólen); contatos ou não das abelhas com as anteras e estigmas; e os padrões de deslocamento das abelhas na flor, durante a coleta de recursos alimentares. O tempo de permanência na flor foi submetido à análise discriminante, realizada com o programa Statística (Statistica for Windows user's guide, 2007).

Os resultados obtidos foram submetidos à análise de variância, pelo teste de Tukey, a 5\% de probabilidade. Os gráficos foram elaborados com auxílio do Programa Sigma Plot (2006).

\section{Resultados e Discussão}

Quanto à altura dos frutos $(\mathrm{cm})$, os tratamentos tiveram efeito apenas na cultivar Aromas, que 
apresentou maiores valores com a polinização livre (Figura 1). Não houve diferença significativa entre os tratamentos de polinização e o diâmetro dos frutos. Esse resultado difere dos de Roselino et al. (2009), que constataram que as flores de morangueiro, visitadas por abelhas, resultam em frutos com maiores diâmetros.

Quanto à massa de matéria fresca por fruto, os efeitos dos tratamentos diferiram de acordo com a cultivar
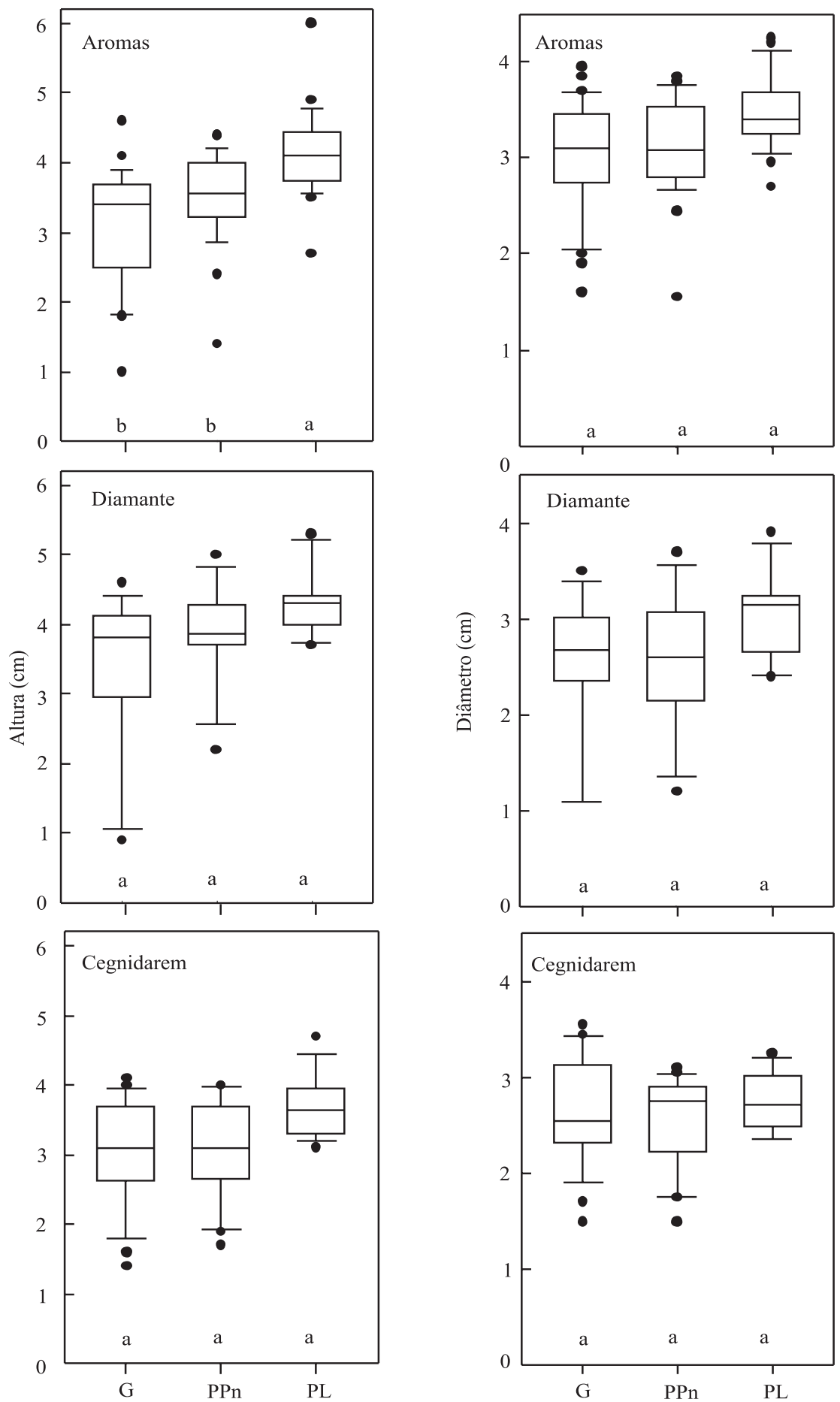
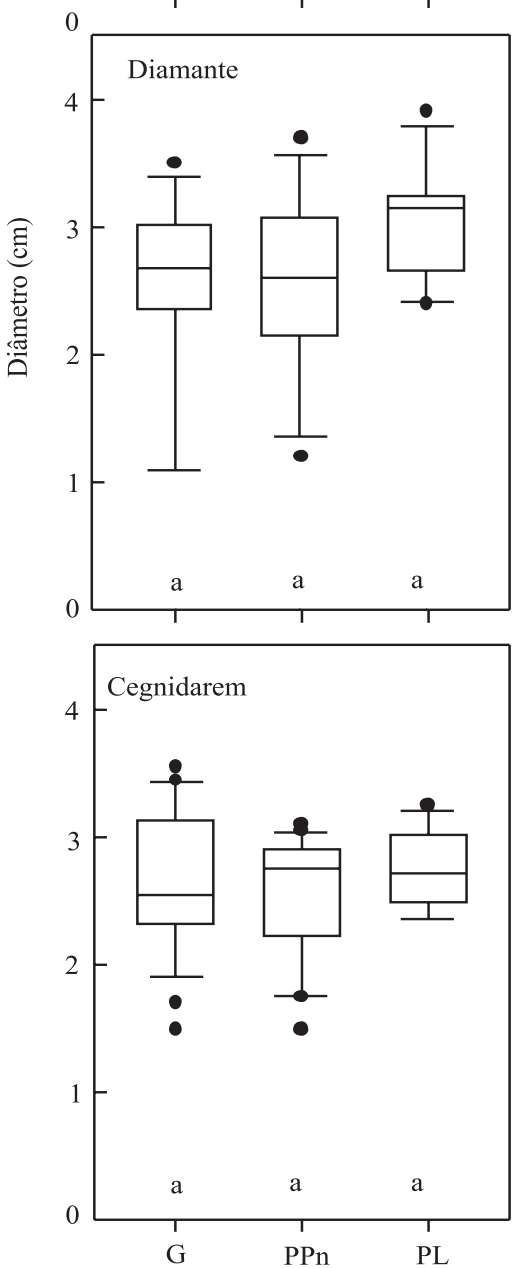
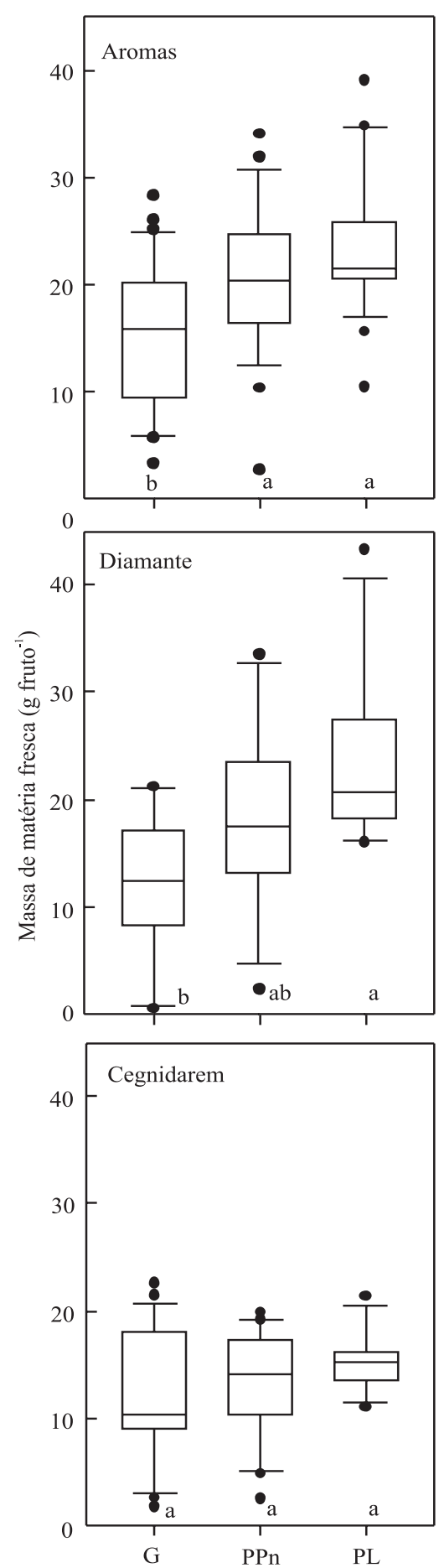

Figura 1. Altura, diâmetro e massa de matéria fresca por fruto das cultivares de morangueiro Aromas, Diamante e Cegnidarem, submetidas aos tratamentos: G, autopolinização; PPn, polinização por Plebeia nigriceps; e PL, polinização livre. Médias seguidas de letras iguais não diferem entre si, pelo teste de Tukey, a 5\% de probabilidade. 
avaliada (Figura 1). Em 'Aromas', os tratamentos com polinização livre e por $P$. nigriceps proporcionaram frutos com massa superior ao tratamento com autopolinização. Em 'Diamante', o tratamento PL apresentou as maiores massas por fruto, sem ter diferido significativamente de PPn que, por sua vez, não diferiu de G. Já em 'Cegnidarem', os tratamentos não produziram efeito sobre a massa de matéria fresca dos frutos. Esses resultados indicam a importância da polinização por insetos para as cultivares Aromas e Diamante. Roselino et al. (2009) também constataram efeito da visitação das flores por abelhas na massa de matéria fresca dos frutos.

Observa-se que uma colônia de $P$. nigriceps apenas foi eficiente para a polinização da cultivar Aromas, que apresentou diferença significativa em altura e peso de frutos, em comparação ao tratamento de autopolinização (Figura 1). A ausência de diferença significativa entre PPn e G, nas demais cultivares, pode estar relacionada à inadequação do número de colmeias utilizado para a polinização, em relação ao número de plantas utilizadas nos experimentos.

A contribuição dos diferentes tratamentos de polinização à massa dos frutos diferiu entre as cultivares estudadas (Tabela 1). A autopolinização apresentou a maior contribuição em todas as cultivares. Contudo verificou-se que as demais formas de polinização também contribuem para o aumento na massa dos frutos, especialmente em 'Aromas' e 'Diamante'. A cultivar Cenigdarem foi a que menos respondeu aos efeitos do vento e do livre acesso dos insetos, bem como à polinização exclusiva com P. nigriceps. Zebroswka (1998) analisou seis cultivares de morangueiro e verificou que é muito variável a contribuição da autopolinização (12 a 48\%) e da polinização por insetos (14 a 67\%) sobre o peso dos frutos. Malagodi-Braga (2002) também avaliou a contribuição percentual de diferentes tratamentos de polinização, quanto à massa de frutos primários

Tabela 1. Contribuição (\%) dos diferentes agentes de polinização à massa $(\mathrm{g})$ de matéria fresca de frutos primários de cultivares de morangueiro, em ambiente protegido, a partir da aplicação da fórmula adaptada proposta por Zebrowska (1998).

\begin{tabular}{lccc}
\hline Contribuição & 'Aromas' & 'Diamante' & 'Cegnidarem' \\
\hline Vento e insetos (polinização livre) & 12,4 & 23,4 & 12,5 \\
Plebeia nigriceps & 22,6 & 24,6 & 8,5 \\
Autopolinização & 65,0 & 52,0 & 79,0 \\
\hline
\end{tabular}

de morangueiro, e constatou que a autopolinização espontânea contribuiu com $69,5 \%$ da massa de matéria fresca dos frutos na cultivar Sweet Charlie, enquanto na Oso Grande esse valor caiu para 43,7\%. De acordo com a autora, a contribuição da polinização pelo vento varia entre as cultivares, com $29 \%$ em Sweet Charlie e 45,3\% em Oso Grande. A contribuição por insetos à polinização foi mais acentuada na 'Oso Grande'. Assim, para o cultivo de morangueiro em ambiente protegido, deve-se considerar a polinização como fator de produção, especialmente nas cultivares Aromas e Diamante.

Antunes et al. (2007) verificaram que a presença da abelha jataí em ambiente protegido tem significativa importância no aumento da produtividade das cultivares 'Oso Grande', 'Tudla' e 'Chandler', e contribui para um aumento no percentual de frutos comercializáveis. Os autores constataram que a cultivar Dover foi menos dependente de agentes polinizadores. Para Calvete et al. (2010), a utilização de Apis mellifera como agente polinizador na cultivar Camarosa proporciona redução no percentual de frutos deformados. No presente trabalho, o maior percentual de frutos deformados foi obtido no tratamento com autopolinização, nas três cultivares avaliadas (Tabela 2). Esses valores excederam $70 \%$, na cultivar Diamante, e $60 \%$ na Aromas; entretanto, verificou-se que na Cegnidarem esse valor não ultrapassou 30\%. Zebrowska (1998), ao avaliar a influência da autopolinização e da polinização pelo vento e por insetos na produtividade de diferentes cultivares de morangueiro, constatou maior produção de frutos deformados no tratamento com autopolinização $(72,32 \%)$ e valores significativamente menores na polinização pelo vento (34\%) e na polinização livre $(7,36)$. De acordo com o autor, a autogamia resulta, geralmente, em distorção no formato dos frutos e em menor produção comercial, em comparação com o desempenho após a polinização por insetos. Esse resultado pode ser explicado pelos fatos de os aquênios que apresentam óvulos fecundados liberarem o hormônio que estimula o crescimento do receptáculo

Tabela 2. Incidência (\%) de frutos deformados, em três cultivares de morangueiro submetidas a diferentes tratamentos e polinização.

\begin{tabular}{lccc}
\hline Tratamento & 'Aromas' & 'Diamante' & 'Cegnidarem' \\
\hline Polinização livre & 16,0 & 18,2 & 28,6 \\
Plebeia nigriceps & 42,9 & 66,7 & 42,9 \\
Autopolinização & 76,7 & 92,9 & 58,3 \\
\hline
\end{tabular}


(Free, 1993) e de a forma dos frutos do morangueiro depender do percentual de óvulos fertilizados e da sua distribuição ao redor do receptáculo; assim, para a obtenção de frutos sem deformações, é necessária uma distribuição uniforme de pólen sobre os estigmas (Malagodi-Braga, 2002).

No presente trabalho, a maior contribuição da polinização por insetos à produtividade de morangueiro está mais relacionada à redução do percentual de frutos deformados do que à massa dos frutos em si. Verificaram-se as seguintes reduções nos percentuais de frutos deformados: 33,8\% na 'Aromas'; 26,2\% na 'Diamante'; e $15,5 \%$ na 'Cegnidarem', no tratamento em que foi utilizada a polinização por $P$. nigriceps, em comparação à autopolinização (Tabela 2). Entretanto, os percentuais de frutos deformados, no tratamento com $P$. nigriceps, foram superiores aos obtidos no tratamento com polinização livre (Tabela 2). Esse resultado pode ser atribuído à presença de diferentes espécies de polinizadores no tratamento com livre visita de insetos. Para alguns autores, flores de morangueiro visitadas por diferentes espécies de polinizadores, que apresentam padrões distintos de comportamento em suas visitas às flores, produzem frutos sem deformação, o que mostra que há um efeito de complementaridade no processo de polinização da cultura (Chagnon et al., 1993; Malagodi-Braga \& Kleinert, 2007). Esse resultado poderia, ainda, estar relacionado a um número insuficiente de colônias de P. nigriceps para a polinização do número de plantas proposta nas áreas de estudo. Kakutani et al. (1993) mostraram que Trigona minangkabau poliniza flores de morangueiro tão bem quanto $A$. mellifera, entretanto mais indivíduos são necessários para alcançar um sucesso semelhante ao da polinização obtida por meio das abelhas melíferas. Antunes et al. (2007) verificaram que o número de visitas realizadas pela abelha jataí, às flores de morangueiro, não diferiu entre as cultivares estudadas em testes com duas e quatro colmeias. Porém, um maior número de visitas foi observado nos testes com quatro colmeias.

Malagodi-Braga \& Kleinert (2004) constataram que os valores médios do número de frutos de valor comercial da cultivar 'Oso Grande' foram sempre inferiores nos tratamentos com autopolinização, em comparação à polinização livre e promovida por abelhas jataí. Entretanto, quanto à forma dos frutos, não constataram diferença significativa entre os tratamentos com abelhas jataí e a polinização livre. Roselino et al. (2009) submeteram flores de 'Camarosa' a diferentes tratamentos de polinização e verificaram que o percentual de frutos deformados foi de $23 \%$, no tratamento sem abelhas, $2 \%$ em ambiente protegido com abelhas, e de $13 \%$ no tratamento com polinização livre. De acordo com os autores, os estigmas da flor de morangueiro tornam-se receptivos antes de o pólen estar disponível, o que favorece a polinização cruzada. Para Malagodi-Braga (2002), o baixo percentual de frutos sem deformações, obtidos em testes de autopolinização em morangueiros 'Sweet Charlie' e 'Oso Grande', foi ocasionado pelo distanciamento entre as anteras e os estigmas superiores e pelo padrão de maturação dos estames e dos pistilos das flores.

Em relação ao comportamento de $P$. nigriceps, nas flores de morangueiro, verificou-se que o néctar foi o principal recurso obtido, tendo representado $95 \%$ das coletas durante as visitas das operárias às flores de todas as cultivares, e somente $5 \%$ de néctar e pólen. Em apenas $20 \%$ das observações, as abelhas transportavam pólen nas corbículas (Tabela 3).

Malagodi-Braga \& Kleinert (2007) verificaram que o principal recurso obtido nas flores de morangueiro difere entre as espécies de abelhas. No presente trabalho, durante as visitas às flores, operárias de P. nigriceps tocaram os pistilos $(88,33 \%)$ e as anteras (40\%) (Tabela 3). O tempo de permanência, ou seja, de visita de $P$. nigriceps às flores de morangueiro apresentou diferença significativa $(p=0,018)$ apenas entre as cultivares 'Aromas' e 'Cegnidarem'. Esse tempo de visita também é variável de acordo com a espécie de polinizador. É possível que 'Aromas' tenha sido

Tabela 3. Média \pm desvio padrão do tempo de visita de Plebeia nigriceps nas flores de três cultivares de morangueiro, em ambiente protegido, e valores percentuais de variáveis relacionadas ao comportamento da espécie ${ }^{(1)}$.

\begin{tabular}{lccc}
\hline Variável & $\begin{array}{c}\text { 'Aromas' } \\
(\mathrm{n}=25)\end{array}$ & $\begin{array}{c}\text { 'Diamante' } \\
(\mathrm{n}=6)\end{array}$ & $\begin{array}{c}\text { 'Cegnidarem' } \\
(\mathrm{n}=29)\end{array}$ \\
\hline Tempo de visita (s) & $114 \pm 54 \mathrm{a}$ & $34 \pm 22 \mathrm{ab}$ & $45 \pm 39 \mathrm{~b}$ \\
Presença de pólen na corbícula (\%) & 8 & 0 & 34 \\
Recurso coletado (néctar) (\%) & 92 & 100 & 96 \\
Recurso coletado (néctar/pólen) (\%) & 8 & 0 & 4 \\
Contato com anteras (\%) & 44 & 50 & 34 \\
Contato com pistilos (\%) & 100 & 83 & 79 \\
Visita a todas as regiões do receptáculo (\%) & 48 & 16 & 27 \\
\hline
\end{tabular}

${ }^{(1)}$ Médias seguidas de letras iguais não diferem pela análise discriminante, a $5 \%$ de probabilidade, com valores de p obtidos a partir do cálculo da distância de Mahalanobis. 
mais beneficiada com a polinização por $P$. nigriceps, pois o tempo de visita às abelhas nas flores foi maior. Esse benefício pode estar relacionado a um número maior de estigmas tocados pelas abelhas e, por consequência, polinizados. Constatou-se que $48 \%$ das abelhas observadas nas flores dessa cultivar tocavam estigmas de todas as regiões do receptáculo (ápice, centro e base). Além disso, a cultivar mais beneficiada com relação à massa de matéria fresca por fruto, na polinização por P. nigriceps, foi 'Aromas' (Figura 1), o que indica relação positiva entre o comportamento da espécie de abelha nas flores e a produtividade da cultura.

Com base nos resultados, $P$. nigriceps adapta-se bem à casa de vegetação e pode forragear nas flores de morangueiro durante todo o dia, portanto, apresenta potencial para polinização da cultura em ambiente protegido. Entretanto, com relação aos percentuais de frutos deformados, no tratamento que utilizou polinização por $P$. nigriceps, verificou-se que os valores foram superiores em comparação aos obtidos no tratamento de polinização livre.

\section{Conclusões}

1. Em ambiente protegido a polinização entomófila tem contribuição variada à massa de matéria fresca dos frutos, de acordo com a cultivar.

2. As cultivares apresentam sensibilidade variada à autopolinização, no que se refere à incidência de frutos deformados.

3. A interferência da polinização entomófila na produtividade do morangueiro está mais relacionada à redução do percentual de frutos deformados do que ao aumento da massa dos frutos em si.

4. O comportamento de $P$. nigriceps indica que a espécie apresenta potencial para polinização da cultura do morangueiro em ambiente protegido.

\section{Referências}

ANTUNES, O.T.; CALVETE, E.O.; ROCHA, H.C.; NIENOW, A.A.; CECCHETTI, D.; RIVA, E.; MARAN, R.E. Produção de cultivares de morangueiro polinizadas pela abelha jataí em ambiente protegido. Horticultura Brasileira, v.25, p.94-99, 2007.

BIESMEIJER, J.C.; SLAA, E.J. Information flow and organization of stingless bee foraging. Apidologie, v.35, p.143-157, 2004.

CALVETE, E.O.; ROCHA, H.C.; TESSARO, F.; CECCHETI, D.; NIENOW, A.A.; LOSS, J.T. Polinização de morangueiro por Apis mellifera em ambiente protegido. Revista Brasileira de Fruticultura, v.32, p.181-188, 2010.

CHAGNON, M.; GINGRAS, J.; OLIVEIRA, D. Complementary aspects of strawberry pollination bee honey and indigenous bees. Journal of Economic Entomology, v.86, p.416-420, 1993.

FERNANDES JÚNIOR, F.; FURLANI, P.R.; RIBEIRO, I.J.A.; CARVALHO, C.R.L. Produção de frutos e estolhos do morangueiro em diferentes sistemas de cultivo em ambiente protegido. Bragantia, v.61, p.25-34, 2002.

FREE, J.B. Insect pollination of crops. London: Academic Press, 1993. 768p.

HEARD, T.A. The hole of stingless bees in crop pollination. Annual Reviews of Entomology, v.44, p.183-206, 1999.

JAYCOX, E.R. Pollination of strawberries. American Bee Journal, n.110, p.176- 177, 1970.

KAKUTANI, T.; IOUE, T.; TEZUCA, T.; MAETA, Y. Pollination of strawberry by the stingless bee, Trigona minangkabau, and the honey bee, Apis mellifera: an experimental study of fertilization eficiency. Researches on Population Ecology, v.35, p.95-111, 1993.

MALAGODI-BRAGA, K.S. Estudo de agentes polinizadores em cultura de morango (Fragaria $x$ ananassa Duchesne Rosaceae). 2002. 104p. Tese (Doutorado) - Universidade de São Paulo, São Paulo.

MALAGODI-BRAGA, K.S.; KLEINERT, A. de M.P. Como o comportamento das abelhas na flor do morangueiro (Fragaria $x$ ananassa Duchesne) influencia a formação dos frutos? Bioscience Journal, v.23, p.76-81, 2007.

MALAGODI-BRAGA, K.S.; KLEINERT, A. de M.P. Could Tetragonisca angustula Latreille (Apinae, Meliponini) be effective as strawberry pollinator in greenhouses? Australian Journal of Agricultural Research, v.55, p.771-773, 2004.

NIEH, J.C. Recruitment communication in stingless bees (Hymenoptera, Apidae, (Meliponini). Apidologie, v.35, p.159-182, 2004.

RADMANN, E.B.; BIANCHI, V.J.; OLIVEIRA, R.P. de; FACHINELLO, J.C. Caracterização e diversidade genética de cultivares de morangueiro. Horticultura Brasileira, v.26, p.84-87, 2006.

REICHERT, L.J.; MADAIL, J.C.M. Morango produção: aspectos socioeconômicos. In: SANTOS, A.M. dos; MEDEIROS, A.R.M. de (Ed.). Morango: produção. Pelotas: Embrapa Clima Temperado; Brasília: Embrapa Informação Tecnológica, 2003. p.12-15.

ROSELINO, A.C.; SANTOS, S.B.; HRNCIR, M.; BEGO, L.R. Differences between the quality of strawberries (Fragaria $x$ ananassa) pollinated by the stingless bees Scaptotrigona aff, depilis and Nannotrigona testaceicornis. Genetics and Molecular Research, v.8, p.539-545, 2009.

SIGMA PLOT. Scientifc graphing software. Version 10.0. San Rafael: Hearne Scientific Software, 2006.

SLAA, E.J.; SANCHES CHAVES, L.A.; MALAGODI-BRAGA, K.S.; HOFSTEDE, F.E. Stingless bees in applied pollination: practice and perspectives. Apidologie, v.37, p.293-315, 2006. 
SLAA, E.J.; TACK, A.; SOMMEIJER, M.J. The effect of intrinsic and extrinsic factors on flower constancy in stingless bees. Apidologie, v.34, p.457-468, 2003.

SOMMEIJER, M.J.; RUIJTER, A. Insect pollination in greenhouses. In: 'SPECIALISTS' MEETING HELD IN SOESTERBERG, 1999, Netherlands. Proceedings. Netherlands: Utrecht University, 1999. 220p.

STATISTICA for Windows user's guide. Version 8.0. Tulsa: StatSoft, 2007.
WITTER, S.; BLOCHTEIN, B.; ANDRADE, F.; WOLFF, L.F.; IMPERATRIZ-FONSECA, V.L. Meliponicultura no Rio Grande do Sul: contribuição sobre a biologia e conservação de Plebeia nigriceps (Friese1901) (Apidae, Meliponini). Bioscience Journal, v.23, p.134-140, 2007.

ZEBROWSKA, J. Influence of pollination modes on yield components in strawberry (Fragaria $x$ ananassa Duch.). Plant Breeding, v.117, p.255-260, 1998.

$\overline{\text { Recebido em } 15 \text { de agosto de } 2011 \text { e aprovado em } 9 \text { de dezembro de } 2011}$ 